\title{
Antigenicity of $\beta$-lactoglobulin reduced by combining with oleic acid during dynamic high-pressure microfluidization: Multi-spectroscopy and molecule dynamics simulation analysis
}

\author{
Junzhen Zhong, ${ }^{1 *}$ Shanlin Fu, ${ }^{1}$ Hongda Yu, ${ }^{1}$ Lei Zhou, ${ }^{1}$ Wei Liu, ${ }^{1}$ Chengmei Liu, ${ }^{1}$ and Sangeeta Prakash ${ }^{2}$ \\ ${ }^{1}$ State Key Laboratory of Food Science and Technology, Nanchang University, Nanchang 330047, China \\ ${ }^{2}$ School of Agriculture and Food Sciences, The University of Queensland, St. Lucia, Brisbane, QLD, 4072, Australia
}

\section{ABSTRACT}

Some food components can modulate the antigenicity of $\beta$-lactoglobulin ( $\beta-\mathrm{LG}$ ). This study investigated the role of oleic acid (OA) in reducing the antigenicity of $\beta$-LG. The results indicate the antigenicity of $\beta-\mathrm{LG}$ gradually decreased from 15 (sample with no OA) to $9.86,7.51$, and $6.01 \mu \mathrm{g} / \mathrm{mL}$ when interacting with $\mathrm{OA}$ during dynamic high-pressure microfluidization treatment at $0.1,80$, and $160 \mathrm{MPa}$. Although binding sites (n) of $\beta$-LG combined with OA at $0.1,80$, and $160 \mathrm{MPa}$ decreased from 0.79 to 0.5 and $0.66, \beta-\mathrm{LG}$ had a higher binding affinity $\left(\mathrm{K}_{\mathrm{a}}\right)$ to OA than that of untreated $\beta-\mathrm{LG}$. The values of $\mathrm{K}_{\mathrm{a}}$ for $\beta-\mathrm{LG} / \mathrm{OA}$ at $0.1,80$, and $160 \mathrm{MPa}$ were $5.51 \times 10^{6}, 17.43 \times 10^{6}$, and $49.75 \times$ $10^{6} M^{-1}$, respectively. The molecule dynamic simulation showed that the OA molecules located at both $\beta$-barrel (site 1) interacted with Lys60, Glu62, and Lys69 and outer surface site 2 consisting of Tyr20, Tyr42, Ser21, Glu157, and His161. Additionally, when binding with OA during the dynamic high-pressure microfluidization treatment, the conformation of $\beta-\mathrm{LG}$ changed, reflected by the decrease of fluorescence intensity and total sulfhydryl group content, the increase of surface sulfhydryl group content, and secondary structure changes of $\beta$-LG. These results deduce that some epitopes may be masked by $\mathrm{OA}$ or modified by the conformational changes, resulting in the decline of antigenicity of $\beta-\mathrm{LG}$ molecules.

Key words: $\beta$-lactoglobulin, oleic acid, antigenicity, modulation mechanism, molecule dynamic simulation

\section{INTRODUCTION}

$\beta$-Lactoglobulin is a member of the lipocalin superfamily, involved in the binding and transportation of

Received April 9, 2018.

Accepted September 3, 2018.

*Corresponding author: zhongjunzhen@163.com hydrophobic, amphiphilic, or hydrophilic molecules such as fatty acids, $\alpha$-tocopherol, resveratrol, or folic acid (Loch et al., 2013; Zhang et al., 2014). Fatty acids are the natural main ligands associated with the bovine $\beta-\mathrm{LG}$ in the milk (Barbiroli et al., 2011). Recently, much research has focused on $\beta$-LG fatty acid complexes, mainly studying the effect of the modified $\beta$-LG on its fatty acid-binding properties (Le Maux et al., 2013), the effect of the interaction between $\beta$-LG and fatty acid on the properties of ligand (Zimet and Livney, 2009; Simion et al., 2015a), and the influence of ligand binding on the properties of protein (Fang et al., 2015).

Oleic acid (OA) is the main fatty acid, constituting 20 to $30 \%$ (wt/wt) of the total fatty acid in bovine milk fat (Jensen, 2002). However, very little information is available about the interaction between $\beta-\mathrm{LG}$ and OA with most research focused on the functional properties of $\beta$-LG and OA complex (Simion et al., 2015a,b). Additionally, $\beta$-LG is the major allergen in the milk of many mammals, due to its resistance to gastric digestion as well as to proteolysis, and therefore is transported intact through the intestinal mucosa (Kleber et al., 2004). The existing literature describes $\beta$-LG-fatty acids complexes, primarily with relevance to the effect of interaction between $\beta-\mathrm{LG}$ and fatty acids on their physicochemical and functional properties. However, very limited information is available on the antigenicity effect of $\beta-\mathrm{LG}$ when it interacts with fatty acids, especially $\mathrm{OA}$.

To eliminate the allergenicity of $\beta-\mathrm{LG}$, several methods have been investigated. In our previous work, Zhong et al. (2015) concluded that the antigenicity of $\beta$-LG sharply decreased after conjugation with nystose and $1^{\mathrm{F}}$ - $\beta$-fructofuranosyl nystose. The antigenicity of $\beta$-LG decreased to $70 \%$ when conjugated with monomethoxy polyethylene glycol-succinimidyl carbonates at a molar ratio of $1: 3, \mathrm{pH} 7.0$, and reaction time of $8 \mathrm{~h}$ (Zhong et al., 2016). Furthermore, in their study $\mathrm{Wu}$ et al. (2013) observed that the IgE-binding and 
IgG-binding activities of $\beta$-LG decreased after binding with catechin. The above results suggest that forming $\beta$-LG complex by binding with other food components may be effective in decreasing antigenicity of $\beta$-LG. Dynamic high-pressure microfluidization (DHPM), an emerging homogeneous technology, has been applied in the dairy industry for reduction of microbial populations, preparation of cheese, and improvement of the quality of milk (Zhong et al., 2012). Our previous studies suggest that the antigenicity of $\beta-L G$ was significantly influenced by DHPM treatment, which was related to its conformational changes (Zhong et al., 2012 ). However, information related to the antigenicity of $\beta$-LG modulated by the interaction with $\mathrm{OA}$ during DHPM treatment is quite scarce.

Hence this study investigated the antigenic properties of $\beta$-LG-OA complexes subjected to DHPM treatment that would help understand the real antigenicity changes of $\beta$-LG during milk processing. Therefore, first a mixture of $\beta-\mathrm{LG}$ and $\mathrm{OA}$ was chosen to be treated to DHPM. This was followed by investigating the antigenicity and binding properties of $\beta$-LG-OA complex through indirect competitive ELISA and fluorescence titration experiments. The conformational changes of $\beta$-LG combining with OA during DHPM were investigated by multi-spectroscopy. Further, molecule dynamic simulation of $\beta$-LG-OA complex was performed to explore the interaction between OA and $\beta-\mathrm{LG}$ at the molecular level.

\section{MATERIALS AND METHODS}

\section{Materials}

$\beta$-Lactoglobulin standard (L3908), OA, and anti-rabbit IgG (A6154) were obtained from Sigma Chemical Company (St. Louis, MO). All other reagents used in this study were of analytical grade.

\section{OA/B-LG Complex Preparation}

The $\beta$-LG/OA complex was prepared by mixing $\beta$-LG and OA (mass ratio, 1:4) with $10 \mathrm{~m} M$ Phosphate buffer solution (pH 7.0) as reported previously (Liskova et al., 2011; Zhong et al., 2011). The mixture was then treated to 3 passes in a Microfluidizer processor (model M-110EH-30, Microfluidics, Newton, MA) at pressures of 80 and $160 \mathrm{MPa}$, respectively. This was followed by dialysis of the sample against distilled water and lyophilization to obtain a crude $\beta$-LG/OA complex.

Bovine $\beta$-LG standard was named $\beta-\mathrm{LG}$ (control), and unprocessed $\beta$-LG-OA complex at the atmospheric pressure $(0.1 \mathrm{MPa})$ was named $\beta$-LG-OA $(0.1 \mathrm{MPa})$. Samples of $\beta$-LG that interact with OA during DHPM treatment at 80 and $160 \mathrm{MPa}$ were named $\beta$-LG-OA (80 MPa) and $\beta$-LG-OA (160 MPa), respectively.

\section{Fluorescence Titration Experiments}

Fluorescence titration experiments was conducted to determine the interaction parameters between $\beta$-LG and OA (Le Maux et al., 2013). All experiments were performed with a $10 \mathrm{~mm}$ quartz rectangular cell at $25^{\circ} \mathrm{C}$ that contained $2 \mathrm{~mL}$ of a $10 \mu \mathrm{M} \beta$-LG solution in a 0.01 $M$ sodium phosphate buffer solution ( $\mathrm{pH}$ 7.0). During one point measurements fluorescence of $\beta$-LG was excited at $295 \mathrm{~nm}$ in the presence of increasing amounts $(3-30 \mu M)$ of $\mathrm{OA}$ on a Hitachi F-4500 fluorimeter (Tokyo, Japan). The emission spectra were recorded in the range from 300 to $450 \mathrm{~nm}$. The excitation and emission slit widths were both set at $5 \mathrm{~nm}$. A $50 \mathrm{mM}$ Stock solution of OA was made in ethanol and diluted to $2 \mathrm{~m} M$ before measurements, as described previously by Loch et al. (2011). The inner filter correction was measured using the same procedure as described above on a UV-VIS 2510PC spectrophotometer (Shimadzu, Kyoto, Japan):

$$
\mathrm{F}=\mathrm{F}_{\mathrm{obs}} \times 10^{\left(\mathrm{A}_{295 \mathrm{~nm}}+\mathrm{A}_{340 \mathrm{~nm}}\right) / 2} .
$$

Here $\mathrm{F}$ represents the corrected fluorescence and $\mathrm{F}_{\text {obs }}$ represents the observed fluorescence. $A_{295 \mathrm{~nm}}$ and $A_{340 \mathrm{~nm}}$ are the absorption measured at $295 \mathrm{~nm}$ and $340 \mathrm{~nm}$, respectively. Each measurement was performed in triplicate. Corrected fluorescence data were analyzed using Cogan plot methods:

$$
\begin{gathered}
\mathrm{L}_{\mathrm{t}}=\mathrm{L}_{\text {free }}+\mathrm{L}_{\text {bound }}, \\
\alpha=\frac{\mathrm{F}-\mathrm{F}_{0}}{\mathrm{~F}_{\max }-\mathrm{F}_{0}}, \\
\mathrm{P}(1-\alpha)=\frac{\mathrm{L}_{\mathrm{t}}}{\mathrm{n}}\left(\frac{1}{\alpha}-1\right)-\frac{\mathrm{K}_{\mathrm{a}}}{\mathrm{n}},
\end{gathered}
$$

where $\mathrm{L}_{\mathrm{t}}, \mathrm{L}_{\text {free }}$, and $\mathrm{L}_{\text {bound }}$ represent concentrations of total OA, free OA, and bound OA, respectively. The value of $\alpha$ is defined as the fraction of free binding sites on protein molecules. $\mathrm{F}_{\max }$ represents the fluorescence intensity upon saturation of all the protein molecules, and $\mathrm{F}_{0}$ is the initial fluorescence intensity. $\mathrm{P}$ is the concentration of $\beta-\mathrm{LG}$, and $\mathrm{L}_{\mathrm{t}}$ is the total concentration of $\mathrm{OA}$ in protein solutions. The apparent association constant $\mathrm{K}_{\mathrm{a}}$ and binding sites $\mathrm{n}$ were determined by fitting the equation using GraphPad Prism software (GraphPad Software Inc., La Jolla, CA). 


\section{Antigenicity Analysis}

Antigenicity of all $\beta$-LG samples were determined by indirect competitive ELISA with polyclonal IgG antibodies of rabbit, which are monospecific against $\beta$-LG (Zhong et al., 2014; Meng et al., 2017). Then 2.5 $\mu \mathrm{g} / \mathrm{mL}$ antigen in $0.05 M$ carbonate-bicarbonate coating buffer was used to coat individual wells $(100 \mu \mathrm{L} /$ well) of a 96-well microplate (flat-bottomed; Costar, Corning, Corning, NY) at $4^{\circ} \mathrm{C}$ overnight. The plate was then washed 3 times with ELISA wash solution $(50 \mathrm{mM}$ Tris, $0.14 M \mathrm{NaCl}, 0.05 \%$ Tween 20, pH 8). Each well was blocked with the residual free binding sites for 30 min at room temperature with $1 \%$ pig gelatin in PBS/ Tween solution (PBST). The plate was then washed 6 times with PBST to remove unbound antigen. Then 50 $\mu \mathrm{L}$ of standards or samples diluted in PBST and the same volume of anti- $\beta$-LG-IgY $(10 \mu \mathrm{g} / \mathrm{mL})$ were added to each well and incubated overnight at $4^{\circ} \mathrm{C}$ followed by washing the plate. Subsequently, $100 \mu \mathrm{L}$ of the diluted 1:10,000 anti-rabbit IgG (A6154, Sigma Chemical Co.) was added to each well and incubated for $2 \mathrm{~h}$ at $37^{\circ} \mathrm{C}$. After washing with PBST again, $100 \mu \mathrm{L}$ of the substrate solution (containing $50 \mu \mathrm{L}$ of $\mathrm{H}_{2} \mathrm{O}_{2}$-urea solution and $50 \mu \mathrm{L}$ of tetramethylenbenzidine solution) was added to each of the wells. Then the chromogenic reaction was allowed to develop in the dark for $15 \mathrm{~min}$ at $37^{\circ} \mathrm{C}$. The reaction was terminated by adding $100 \mu \mathrm{L}$ of $2 M \mathrm{H}_{2} \mathrm{SO}_{4}$. Absorption was measured at $450 \mathrm{~nm}$. The antigenic response was calculated from the standard curve as equivalent micrograms of $\beta$-LG per milliliter of sample. All analyses were carried out in triplicate.

\section{Synchronous Fluorescence Spectra Analysis}

Synchronous fluorescence analyses were performed for different $\beta$-LG samples, in a Hitachi spectrofluorimeter (F-4500, Hitachi, Tokyo, Japan) using 10-mm quartz cells and a protein concentration of $0.15 \mathrm{mg} /$ $\mathrm{mL}$ in phosphate buffer solution (10 mM, pH 7.0). The synchronous fluorescence spectra were obtained considering the wavelength intervals $\Delta \lambda=15 \mathrm{~nm}$ and $\Delta \lambda=60 \mathrm{~nm}$ to evidence the tyrosine and tryptophan residues, respectively $\left(\Delta \lambda=\lambda_{\mathrm{em}}-\lambda_{\mathrm{ex}}\right)$ (Varlan and Hillebrand, 2010).

\section{Determination of Surface and Total Sulfhydryl Group}

Surface sulfhydryl (SH) contents of protein samples were determined using Ellman's reagent (Ellman, 1959; Sava et al., 2005). Fifty microliters of each sample was diluted with $4 \mathrm{~mL}$ of standard buffer (0.086 $M$ Tris, $0.09 M$ glycine, $4 \mathrm{mM} \mathrm{Na} 2 \mathrm{EDTA}$; $\mathrm{pH}=8$ ) for surface $\mathrm{SH}$ groups, or urea (8 $M$ in standard buffer) for total
$\mathrm{SH}$ groups. To these samples, $25 \mu \mathrm{L}$ of $5,5^{\prime}$-dithiobis2-nitrobenzoic acid (DTNB; $4 \mathrm{mg}$ of DTNB $/ \mathrm{mL}$ of standard buffer) was added. The absorbance at 412 $\mathrm{nm}$ was measured against a reagent blank after $15 \mathrm{~min}$ (surface $\mathrm{SH}$ groups) or $2 \mathrm{~min}$ (total $\mathrm{SH}$ groups) at $25^{\circ} \mathrm{C}$. The SH contents were calculated by the use of extinction coefficient of 2-nitro-5-thiobenzoate (NTB) at 412 $\mathrm{nm}$ of $13,600 \mathrm{M}^{-1} \mathrm{~cm}^{-1}$ and expressed as micromoles per gram of protein.

\section{Circular Dichroism Spectroscopy}

Far-UV circular dichroism (CD) spectra analyses were run for different samples, using the method proposed by Chen et al. (2005). All the CD spectra were collected using a MOS-450 spectropolarimeter (French Bio-Logic SAS, Claix, France) between 190 and $250 \mathrm{~nm}$ at $25^{\circ} \mathrm{C}$. The concentration of $\beta-\mathrm{LG}$ was $0.1 \mathrm{mg} / \mathrm{mL}$ (for far UV) in $10 \mathrm{~m} M$ sodium phosphate buffer $(\mathrm{pH}$ 7.0). The path length of $0.1 \mathrm{~cm}$ was used for collecting data in the far-UV regions. The scanning condition was $1 \mathrm{~nm}$ step resolution; scans were performed using a 100 $\mathrm{nm} / \mathrm{min}$ scan rate, $2.0 \mathrm{~nm}$ of bandwidth, and 9 scans, corrected by subtracting the buffer baseline spectrum. The CD data were expressed in terms of mean residual ellipticity $\left([\theta] ; \operatorname{mdeg} \cdot \mathrm{cm}^{2} / \mathrm{dmol}\right)$. Structure predictions from CD spectra were obtained using the Contin LL program (de la Hoz and Netto, 2008).

\section{Molecule Docking and Molecule Dynamic Simulation}

The molecule docking and dynamic simulation of interaction between $\mathrm{OA}$ and $\beta-\mathrm{LG}$ was performed as per Evoli et al. (2014) and Trott and Olson (2010) with slight modifications. The crystal structure of $\beta-L G$ (PDB ID: 3NPO) was downloaded from the RCSB Protein Data Bank (http://www.rcsb.org/pdb). The position of 3 missing residues in the loop GH was reconstructed by modeler module in Chimera 1.7 software (Pettersen et al., 2004). The molecular model of OA (PubChem CID:445639) was obtained from the PubChem database (http://pubchem.ncbi.nlm.nih.gov/). Docking of OA to $\beta$-LG was investigated by using AutoDock Vina 3.5 and GROMACS software (both from State Key Laboratory of Food Science and Technology, Nanchang University, China). The water molecule in $\beta$-LG was removed, whereas all hydrogen atoms were added to the macromolecule file. $\beta$-Lactoglobulin is considered as rigid and $\mathrm{OA}$ as fully flexible during docking. The docking procedure consisted of 15 independent runs, each determining the best 9 docking conformations ranked according to the Lamarckian genetic algorithm.

The simulation package GROMACS was used for trajectory production and analysis, in combination 
with GROMOS 56a6 force field (Oostenbrink et al., 2004; Pronk et al., 2013). The topologies of OA was derived from the side chain of Ala and Glu residues in the GROMOS 53a6 force field, as previously described by Rizzuti et al. (2010). In all simulations, $\beta$-LG was solvated in the SPC water model within the center of a rhombic dodecahedron box with a minimum distance of $1 \mathrm{~nm}$ with respect to cell walls, and periodic boundary conditions were applied to prevent edge effects. The ionization state of the system was neutralized by the addition of $10 \mathrm{Na}^{+}$counterions. The system was energy minimized with a steepest descent method for 250 steps. Initial atomic velocities were extracted from a Maxwell-Boltzmann distribution corresponding to 300 $\mathrm{K}$. The temperature was controlled by using a velocityrescaling thermostat (Bussi et al., 2007), with coupling constant of 0.1 ps. Parrinello-Rahman was used to control the pressure, with reference pressure $0.1 \mathrm{MPa}$ and coupling constant 1 ps (Martoňák et al., 2003). The particle-mesh Ewald method was used for computing the electrostatic interactions (Darden et al., 1993; Pérez and Calvo, 1995). Bond distances were constrained by using the P-LINCS algorithm and a time step of $2 \mathrm{fs}$ was used to integrate the equations of motion. The production runs were carried out for $10 \mathrm{~ns}$.

\section{Statistical Analysis}

All experiments were performed in triplicate except for CD analysis that was carried out in quadruplicate. The one-way ANOVA test for significant effects of treatments and assays was determined using SPSS12.0.1 (SPSS Inc., Chicago, IL). Main effect differences were considered significant at $P \leq 0.05$. Mean separations were determined by Tukey's procedure for multiple comparisons.

\section{RESULTS AND DISCUSSION}

\section{Binding Properties of $\beta-L G$ with OA}

Intrinsic fluorescence titration is based on the change in the intensity of $\beta$-LG tryptophan fluorescence. We observed from Figure 1 that the change in relative fluorescence intensity reached a maximum of $11.27 \pm$ $0.06 \%, 10.94 \pm 0.01 \%$, and $11.33 \pm 0.03 \%$ for native $\beta$-LG, $\beta$-LG (80 MPa), and $\beta$-LG (160 MPa), respectively. For the entire titration, the data were fitted using a linear regression to calculate the apparent association constant $\left(\mathrm{K}_{\mathrm{a}}\right)$ and binding sites (n; Table 1$)$. The values of $5.51 \times 10^{6} M^{-1}$ for $\mathrm{K}_{\mathrm{a}}$ and 0.79 for $\mathrm{n}$ of native $\beta$-LG were estimated, and were similar to those obtained $\left(\mathrm{K}_{\mathrm{a}}=1.3 \times 10^{7} M^{-1}, \mathrm{n}=0.82\right)$ by Frapin et

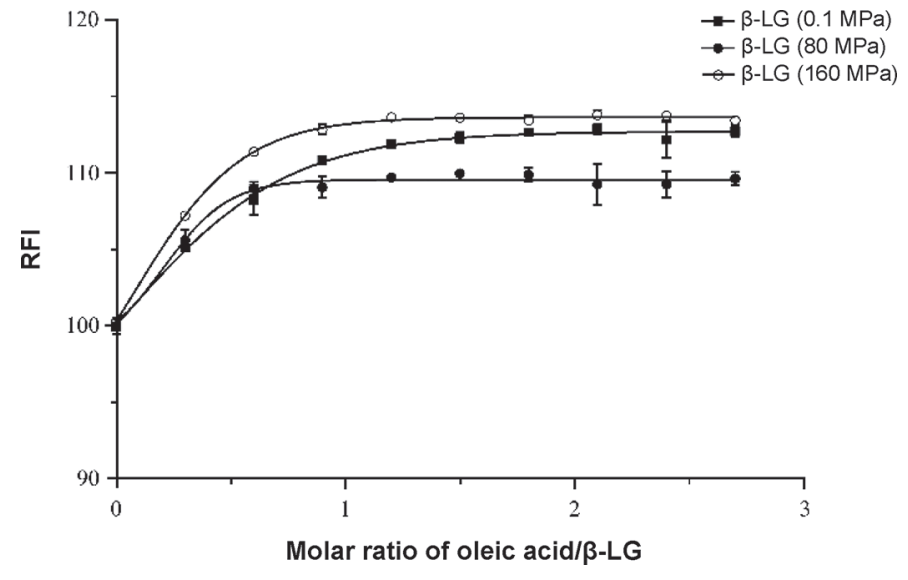

Figure 1. Binding association of oleic acid (OA)/ $\beta$-LG with different forms of $\beta$-LG obtained by fluorescence. $\mathrm{RFI}=$ relative fluorescence intensity. All values are mean $\pm \mathrm{SE} ; \mathrm{n}=3$.

al. (1993). Compared with native $\beta-\mathrm{LG}$, the $\mathrm{n}$ values of $\beta$-LG (80 MPa) and $\beta$-LG (160 MPa) decreased to $0.50 \pm 0.02$ and $0.66 \pm 0.09$, whereas $\mathrm{K}_{\mathrm{a}}$ increased to $17.43 \pm 0.78 \times 10^{6} M^{-1}$ and $49.75 \pm 7.51 \times 10^{6} M^{-1}$, respectively, suggesting the binding affinity of $\mathrm{OA}$ and $\beta$-LG modified by DHPM remarkably increased. From our previous study it was observed that DHPM treatment could induce disaggregation and partial unfolding of $\beta$-LG molecules, but at pressures above $80 \mathrm{MPa}$, the reaggregation of $\beta$-LG occurred (Zhong et al., 2012). This conformation changes of $\beta-\mathrm{LG}$ at pressures $>80$ MPa could modify the binding affinity of the ligands by changing the accessibility of binding sites (O'Neill and Kinsella, 1988; Dufour et al., 1992; Yang et al., 2008). Therefore, the higher binding affinity observed in $\beta$-LG modified by DHPM was a result of partial unfolding of the protein conformation around binding sites at 80 MPa. Several studies have demonstrated the effect of $\beta-\mathrm{LG}$ aggregation on ligand binding affinity, but these effects relied on the structure of the aggregates, the type of ligands, or both (Ron et al., 2010; Shpigelman et al., 2010). The re-aggregation of $\beta-\mathrm{LG}$ at $160 \mathrm{MPa}$ may make it more accessible to bind with OA, hence the higher $\mathrm{K}_{\mathrm{a}}$ value.

Table 1. The apparent association constant $K_{a}$ and binding sites $n$ for different forms of $\beta$-LG with oleic acid (OA) obtained by fluorescence quenching measured (mean $\pm \mathrm{SE} ; \mathrm{n}=3$ )

\begin{tabular}{lccr}
\hline Item & $\begin{array}{c}\mathrm{OA} / \beta-\mathrm{LG} \\
(0.1 \mathrm{MPa})\end{array}$ & $\begin{array}{c}\mathrm{OA} / \beta-\mathrm{LG} \\
(80 \mathrm{MPa})\end{array}$ & $\begin{array}{c}\mathrm{OA} / \beta-\mathrm{LG} \\
(160 \mathrm{MPa})\end{array}$ \\
\hline $\mathrm{K}_{\mathrm{a}}\left(10^{6} M^{-1}\right)$ & $5.51 \pm 0.77^{\mathrm{c}}$ & $17.43 \pm 0.78^{\mathrm{b}}$ & $49.75 \pm 7.51^{\mathrm{a}}$ \\
$\mathrm{n}$ & $0.79 \pm 0.11^{\mathrm{a}}$ & $0.50 \pm 0.02^{\mathrm{b}}$ & $0.66 \pm 0.09^{\mathrm{b}}$
\end{tabular}

${ }^{\mathrm{a}-\mathrm{c}}$ Different letters denote significant differences among different treatments $(P \leq 0.05)$. 


\section{Changes of Antigenicity of $\beta-L G-O A$}

The molecular basis of changes in antigenicity is the inactivation or destruction of epitope structures or increased inaccessibility to epitopes (Besler et al., 2001). The antigenicity of $\beta$-LG (control) was $15.00 \mu \mathrm{g} / \mathrm{mL}$, and after binding with OA, the antigenicity of $\beta$-LGOA (0.1 MPa; $9.86 \mu \mathrm{g} / \mathrm{mL})$ decreased remarkably (Figure 2). The reason for the decline in the antigenicity of $\beta$-LG was that some epitopes were masked by the OA. A similar phenomenon was observed by $\mathrm{Wu}$ et al. (2013), who reported that binding of catechin to $\beta-\mathrm{LG}$ could reduce the antigenicity of protein by the shielding action of the $\beta$-LG epitopes. In our previous research, DHPM modified $\beta$-LG standards showed a remarkable increase in antigenicity when treated to $80 \mathrm{MPa}$ (Zhong et al., 2012). However, the values of antigenicity of $\beta$-LG-OA (80 MPa) and $\beta$-LG-OA $(160 \mathrm{MPa})$ in this study further declined to 7.15 and $6.01 \mu \mathrm{g} / \mathrm{mL}$, respectively, possibly due to changes in protein structure and binding properties of fatty acid bought about by DHPM. To understand the decline in the antigenicity of $\beta$-LG-OA during DHPM treatments, we further investigated the conformational changes of $\beta$-LG-OA at different pressures and the molecule dynamic simulation.

\section{Conformational Changes of $\beta-L G-O A$}

Changes of Synchronous Fluorescence Spectroscopy of $\beta-L G-O A$. The synchronous fluorescence spectra can provide information about the microenvironment around the chromophore molecules. According to Varlan and Hillebrand (2010), the synchronous fluorescence spectra were obtained considering the wavelength intervals $\Delta \lambda=15 \mathrm{~nm}$ and $\Delta \lambda=60 \mathrm{~nm}$ to evidence the tyrosine and tryptophan residues, respectively $\left(\Delta \lambda=\lambda_{\text {em }}-\lambda_{\text {ex }}\right)$.

The changes in synchronous fluorescence spectrum of $\beta$-LG samples for tryptophan and tyrosine residues are shown in Figures $3 \mathrm{~A}$ and 3B, respectively. As can be seen, the fluorescence intensity of tryptophan and tyrosine residues significantly $(P<0.05)$ increased in the presence of OA. Two tryptophan residues, Trp19 and Trp61, are located at the bottom of the calyx and close to the entrance of calyx, respectively, and Trp61 fluorescence is mainly quenched by the Cys66-Cys160 disulfide bond (Keppler et al., 2014). The quenching effect could be compensated by changing conformation of protein due to binding with fatty acids, as previously described by Le Maux et al. (2013). Since the calyx of $\beta-L G$ is the main binding site for fatty acids, we can confirm that the increase in tryptophan's fluorescence intensity is primarily caused by the binding of OA within the calyx. The $\beta$-LG monomer also contains 4 Tyr residues at positions $20,42,99$, and 102 . The Tyr20 and Tyr42 are located in the groove between $\beta$-strand B and helical turn 153-157, and Tyr102 is located in the groove between the $\alpha$-helix and the $\beta$-barrel. Similarly, the fluorescence intensity of tyrosine increased in the presence of OA, implying that the existing secondary binding sites for OA are close to tyrosine residues.

The fluorescence intensity of tyrosine and tryptophan residues of $\beta$-LG-OA (80 MPa) decreased from 930.4 and 247.5 to 547.7 and 174.9 compared with that of $\beta$-LG-OA $(0.1 \mathrm{MPa})$. However, the fluorescence intensity of tyrosine and tryptophan residues of $\beta$-LG-OA (160 MPa) increased to 769.8 and 226.7 compared with that of $\beta$-LG-OA ( $80 \mathrm{MPa}$ ). These changes in the fluorescence intensity of tyrosine and tryptophan residues of $\beta$-LG-OA at different pressure were similar with the binding sites (n) changes as displayed above. Hence it can be deduced that the binding site changes of $\beta-\mathrm{LG}$ during DHPM treatment affect its synchronous fluorescence spectra.

Changes of Surface and Total SH Content of $\beta-L G-O A$. In the native state, the SH groups of $\beta$-LG are inaccessible to DTNB. At $\mathrm{pH} 8$, however, the dimer starts to dissociate, followed by critical conformational changes in $\beta$-LG with exposure of the reactive free sulfhydryl group (Shimada and Cheftel, 1988; Iametti et

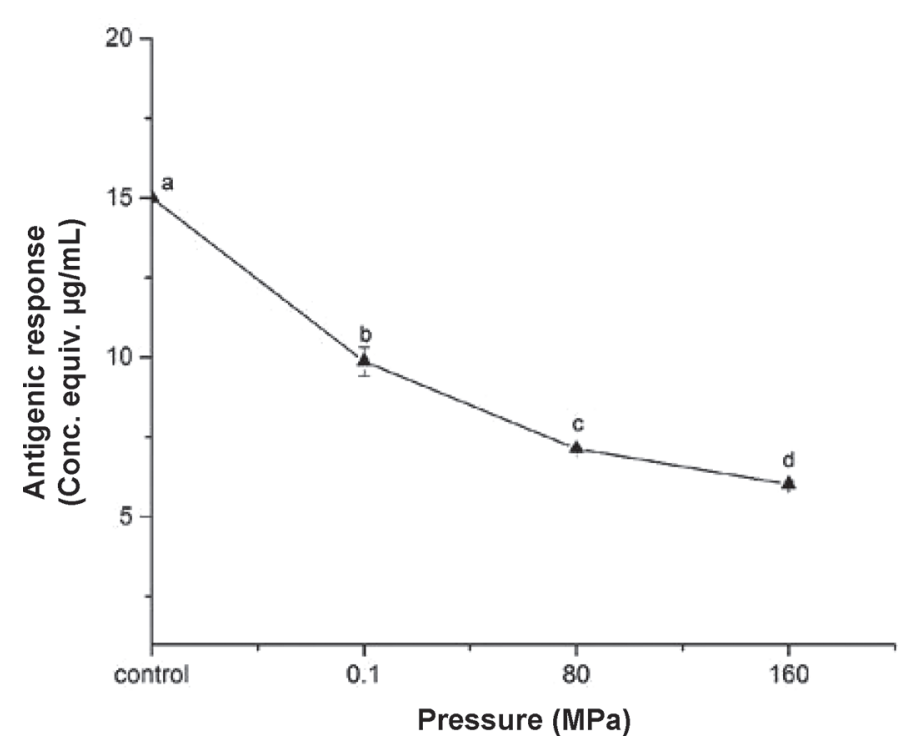

Figure 2. Antigenicity of $\beta$-LG (control), $\beta$-LG-oleic acid (OA; 0.1 $\mathrm{MPa}$ ), $\beta$-LG-OA (80 MPa), and $\beta$-LG-OA (160 MPa). Different letters $(\mathrm{a}-\mathrm{d})$ denote significant differences across different treatments $(P \leq$ 0.05). conc. equiv. = concentration equivalents. All values are mean $\pm \mathrm{SE} ; \mathrm{n}=3$. 
A

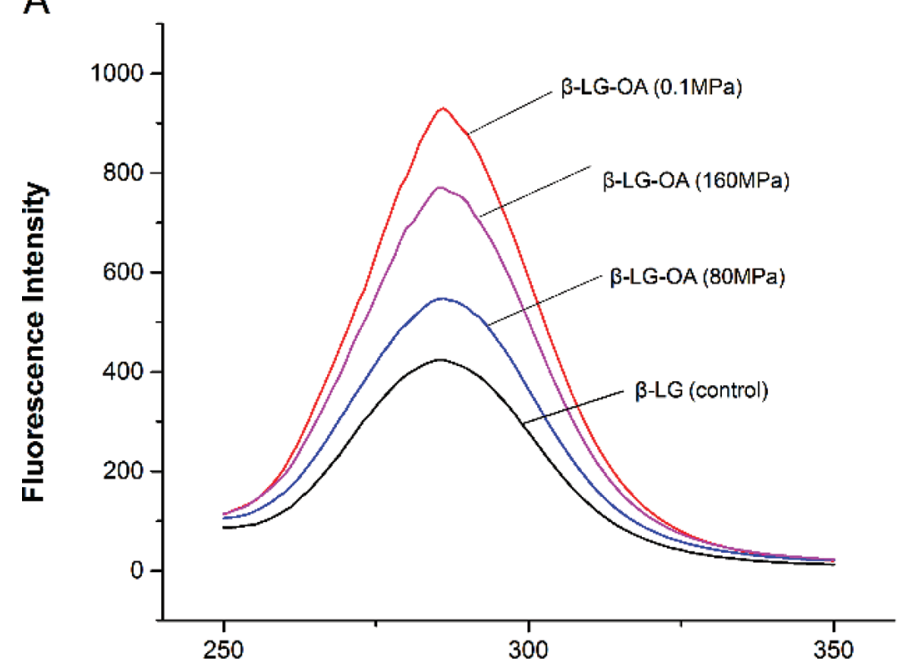

B

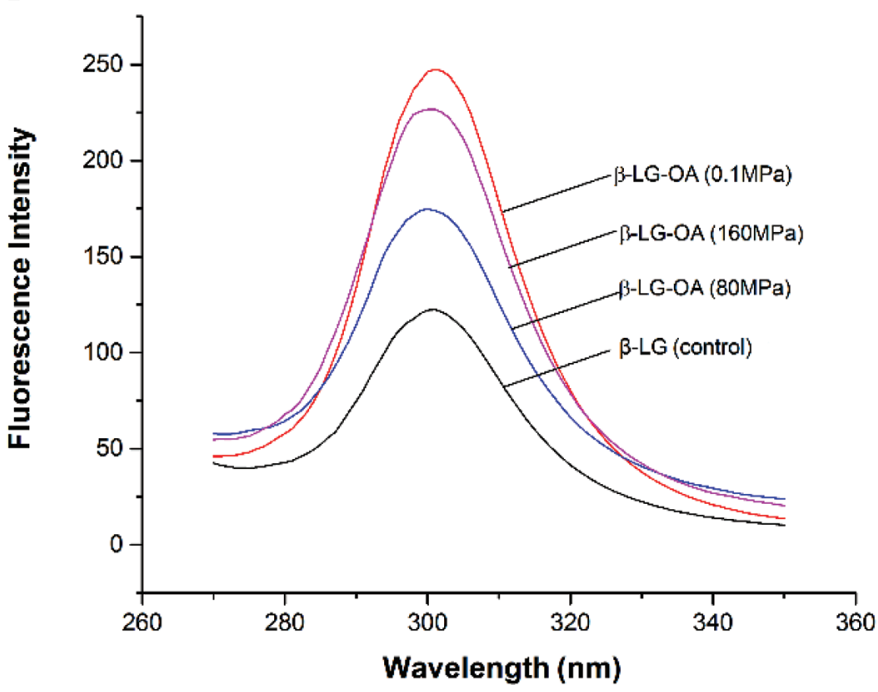

Figure 3. Synchronous fluorescence spectrum of $\beta$-LG (control), $\beta$-LG-oleic acid (OA; $0.1 \mathrm{MPa}), \beta$-LG-OA (80 MPa), and $\beta$-LG-OA (160 MPa). (A) $\lambda=60 \mathrm{~nm}$; (B) $\lambda=15 \mathrm{~nm}$.

al., 1997). The surface SH group content was found to be $11.12 \mu \mathrm{mol} / \mathrm{g}$ of protein for $\beta$-LG (control). It was observed that after binding with $\mathrm{OA}$, the surface $\mathrm{SH}$ content of $\beta$-LG-OA (0.1 MPa) decreased to $9.58 \mu \mathrm{mol} / \mathrm{g}$ of protein (Figure 4). This decrease could be due to the bound fatty acids that stabilized the structure between the barrel itself and the long helix, where the Cys121 was buried (Barbiroli et al., 2011). However, surface $\mathrm{SH}$ content of $\beta$-LG-OA (80 MPa) and $\beta$-LG-OA (160 $\mathrm{MPa}$ ) increased to 9.82 and $13.23 \mu \mathrm{mol} / \mathrm{g}$, respectively, which were higher than that of $\beta-\mathrm{LG}(0.1 \mathrm{MPa})$. The increased SH group may have resulted from structural changes of protein molecule induced by DHPM (Zhong et al., 2012).
The total SH group's content for $\beta-\mathrm{LG}$ standard was $54.6 \mu \mathrm{mol} / \mathrm{g}$ of protein. In our study, a similar value of $53.67 \pm 0.81 \mu \mathrm{mol} / \mathrm{g}$ of proteins was obtained for $\beta$-LG (control). The binding of OA to $\beta$-LG did not remarkably affect the total $\mathrm{SH}$ content, with a total $\mathrm{SH}$ content of $53.73 \pm 0.69 \mu \mathrm{mol} / \mathrm{g}$ for $\beta$-LG-OA $(0.1$ $\mathrm{MPa})$. However, the total SH content of $\beta$-LG-OA (80 $\mathrm{MPa})$ and $\beta$-LG-OA (160 MPa) decreased to $48.10 \pm$ 1.32 and $44.93 \pm 0.86 \mu \mathrm{mol} / \mathrm{g}$, respectively. The results from this study are in agreement with Funtenberger et al. (1997) and Zhong et al. (2012), who observed a decrease in the total SH content at high pressure, due to their participation in the covalent bonding.

Changes of $C D$ Analysis of $\beta-L G-O A$. $\beta$-Lactoglobulin is predominantly a $\beta$-sheet protein, containing 9 anti-parallel $\beta$-strands and one 3 -turn $\alpha$-helix at the $\mathrm{C}$ terminus of the molecule (Shibayama, 2008). The CD spectra displayed a negative extreme around $217 \mathrm{~nm}$, a crossing zero dichroism at $203 \mathrm{~nm}$, and a positive maximum around $195 \mathrm{~nm}$, suggesting a high content of $\beta$-strands, in accordance with the secondary structure (Figure 5). The secondary structure composition of $\beta-\mathrm{LG}$ (control) in percentage was approximately $\alpha$-helix, $13.1 \%$; $\beta$-sheet, $31.2 \%$; $\beta$-turn, $22.6 \%$; and unordered coil, 33.1\% (the inset of Figure $5)$. The calculated values were in the range of secondary structure content of native $\beta$-LG determined by other researchers using CD (Qi et al., 1997; Croguennec et al., 2004).

Some studies found that the secondary structure of $\beta-\mathrm{LG}$ was almost maintained after binding with fatty

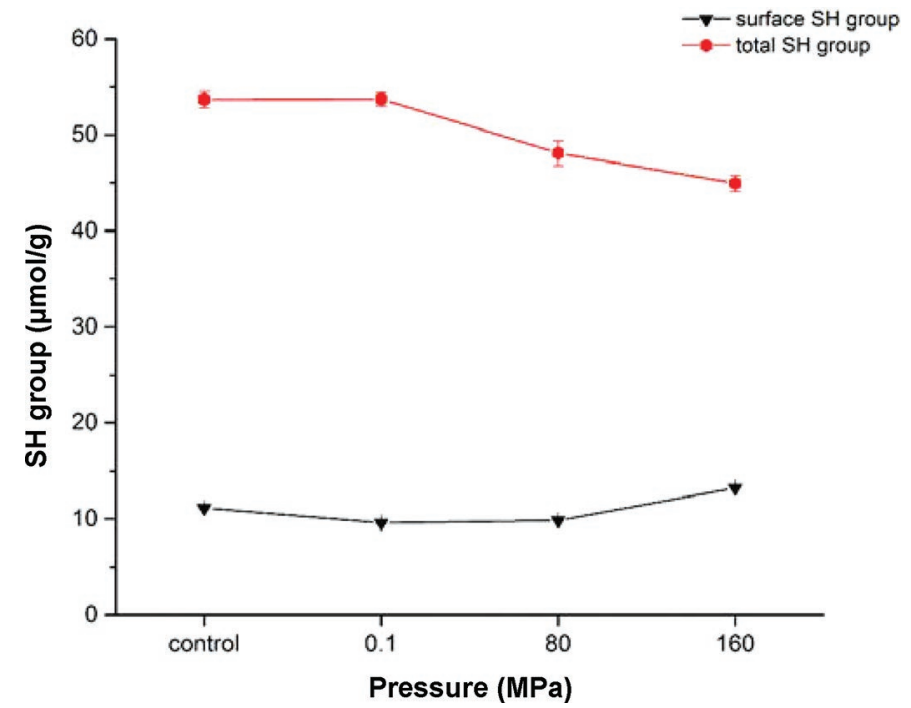

Figure 4. Surface sulfhydryl (SH) contents and total SH contents of $\beta$-LG (control), $\beta$-LG-oleic acid (OA; $0.1 \mathrm{MPa}), \beta$-LG-OA (80 $\mathrm{MPa})$, and $\beta$-LG-OA (160 MPa). All values are mean $\pm \mathrm{SE} ; \mathrm{n}=3$. 
acids (Barbiroli et al., 2011). In this work, the spectrum of the $\beta$-LG-OA (0.1 MPa) showed a slight increase in ellipticity of 2 negative maximums compared with that of $\beta$-LG (control), in accordance with the decreasing in $\alpha$-helix structure content and the increasing in $\beta$-sheet structure content. This indicated that part of the $\alpha$-helix of $\beta$-LG may be extended to $\beta$-sheet whereas $\beta$-LG binds with OA. With $\beta$-LG-OA (80 MPa), values of negative peaks significantly decreased at $214 \mathrm{~nm}$, accompanied by a further increase in the percentage of $\beta$-strands from 31.2 to $38.4 \%$. However, it was also observed that the $\beta$-sheet structure content of $\beta$-LGOA (160 MPa) decreased from 38.40 to $31.80 \%$, which results from the $\beta$-sheet being masked by reaggregation of $\beta$-LG.

Molecule Docking and Molecule Dynamic Simulation Results. To further investigate the interaction between $\mathrm{OA}$ and $\beta-\mathrm{LG}$, the molecule docking simulation was verified using AutoDock Vina and GROMACS and 9 modes were obtained. The docking parameters are shown in Table 2. The best mode was the docking conformation with the lowest binding affinity $(-7.2,-4.0$, and $-4.1 \mathrm{kcal} / \mathrm{mol})$. Thus, mode 1 was selected as having the most suitable results for subsequent analysis. With 3-dimensional docking mode (Figure 6A), it was observed that one OA molecule was inserted into the $\beta$-barrel cavity of $\beta$-LG (site 1 ), and the other binding sites were on the protein surface located in 2 distinct regions: one (site 2) was between

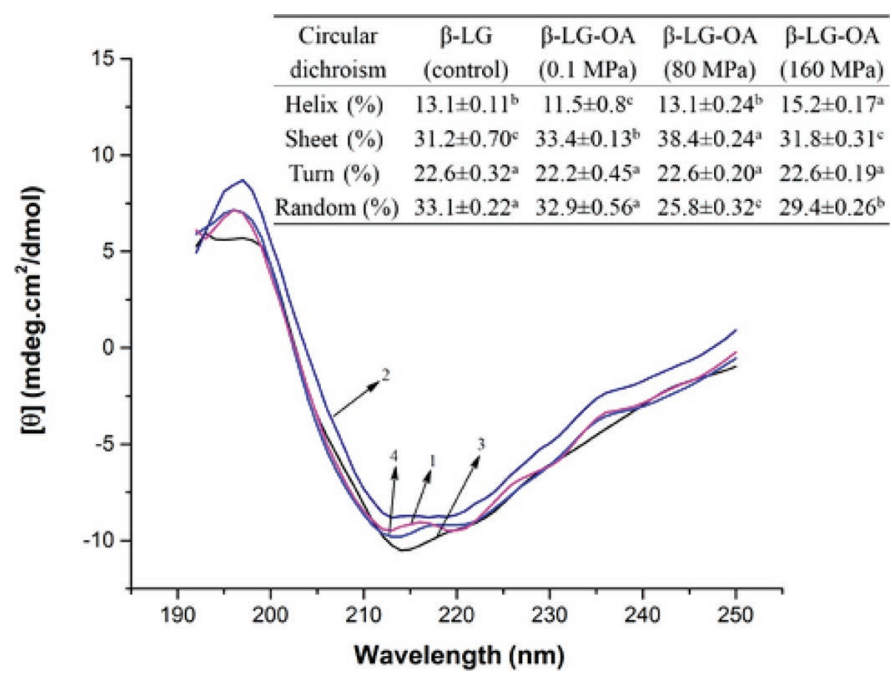

Figure 5. Far-UV circular dichroism spectra of secondary structures of samples. 1 to 4 represent $\beta$-LG (control), $\beta$-LG-oleic acid (OA; $0.1 \mathrm{MPa}), \beta$-LG-OA (80 MPa), and $\beta$-LG-OA (160 MPa), respectively. $[\theta]=$ mean residual ellipticity. The inset shows calculated percentage content of secondary structures of $\beta$-LG (control), $\beta$-LG-OA (0.1 $\mathrm{MPa}$ ), $\beta$-LG-OA (80 MPa), and $\beta$-LG-OA (160 MPa). Different letters $(\mathrm{a}-\mathrm{c})$ denote significant differences across different treatments $(P \leq$ $0.05)$.
Table 2. The results of docking (affinity; kcal/mol) by AutoDock Vina 3.5 (State Key Laboratory of Food Science and Technology, Nanchang University, China)

\begin{tabular}{lccc}
\hline & \multicolumn{3}{c}{ Site } \\
\cline { 2 - 4 } Mode & 1 & 2 & 3 \\
\hline 1 & -7.2 & -4.0 & -4.1 \\
2 & -7.1 & -3.8 & -4.1 \\
3 & -6.5 & -3.8 & -3.9 \\
4 & -6.5 & -3.7 & -3.9 \\
5 & -6.2 & -3.6 & -3.9 \\
6 & -6.0 & -3.5 & -3.8 \\
7 & -6.0 & -3.4 & -3.7 \\
8 & -5.9 & -3.4 & -3.7 \\
9 & -5.7 & -3.4 & -3.7 \\
\hline
\end{tabular}

the helical turn 153-157 and $\beta$-strand $\mathrm{B}$, and the other one (site 3 ) was between the $\alpha$-helix and $\beta$-strand I (Figure 6A). These results reveal that the most stable binding site was site 1 , and the second stable binding sites were site 2 and site 3 .

After molecular dynamics simulation, it is clear from Figure $6 \mathrm{~B}$ that the OA molecules located at both $\beta$-barrel (site 1) and outer surface site 2 still remain and are accompanied with a slight modification of the protein structure that helped to stabilize OA. But OA located at site 3 disappeared. Evoli et al. (2014) also reported that the palmitic acid in site 3 migrated from its starting position during the simulation, indicating that the site 3 was not a reliable binding sites for fatty acid. For unsaturated OA in site 1, the starting U-shape conformation obtained from docking simulation was extended after molecule dynamic simulation (Figure 6, represented in blue), and the carboxylate group of the OA interacted with polar residues Lys60, Glu62, and Lys69 by electrostatic interactions and a hydrogen bond that agrees well with the results obtained by Loch et al. (2013) and Evoli et al. (2014). The outer surface site 2 was a small protein pocket consisting of residues Tyr20, Tyr42, Ser21, Glu157, and His161, which was also identified by molecular docking for epigallocatechin-3-gallate (Wu et al., 2011) and palmitic acid (Evoli et al., 2014). After molecule dynamics simulation, the OA molecule penetrated the protein surface and attached its head-group to the interior (Figure 6, OA represented in yellow) by hydrogen bonding with residues Ser21 and His161.

Combining the molecule dynamic simulation model with the conformational changes in protein, it was suggested that the binding process between $\beta-L G$ and OA induced by DHPM was accompanied by changes in epitopes. The antigenicity of $\beta$-LG relies on the integrality of the epitopes, being widely spread along the 162 AA. Selo et al. (1999) have reported that the major epitopes of $\beta-L G$ are fragments (41-60), (102-124), and 


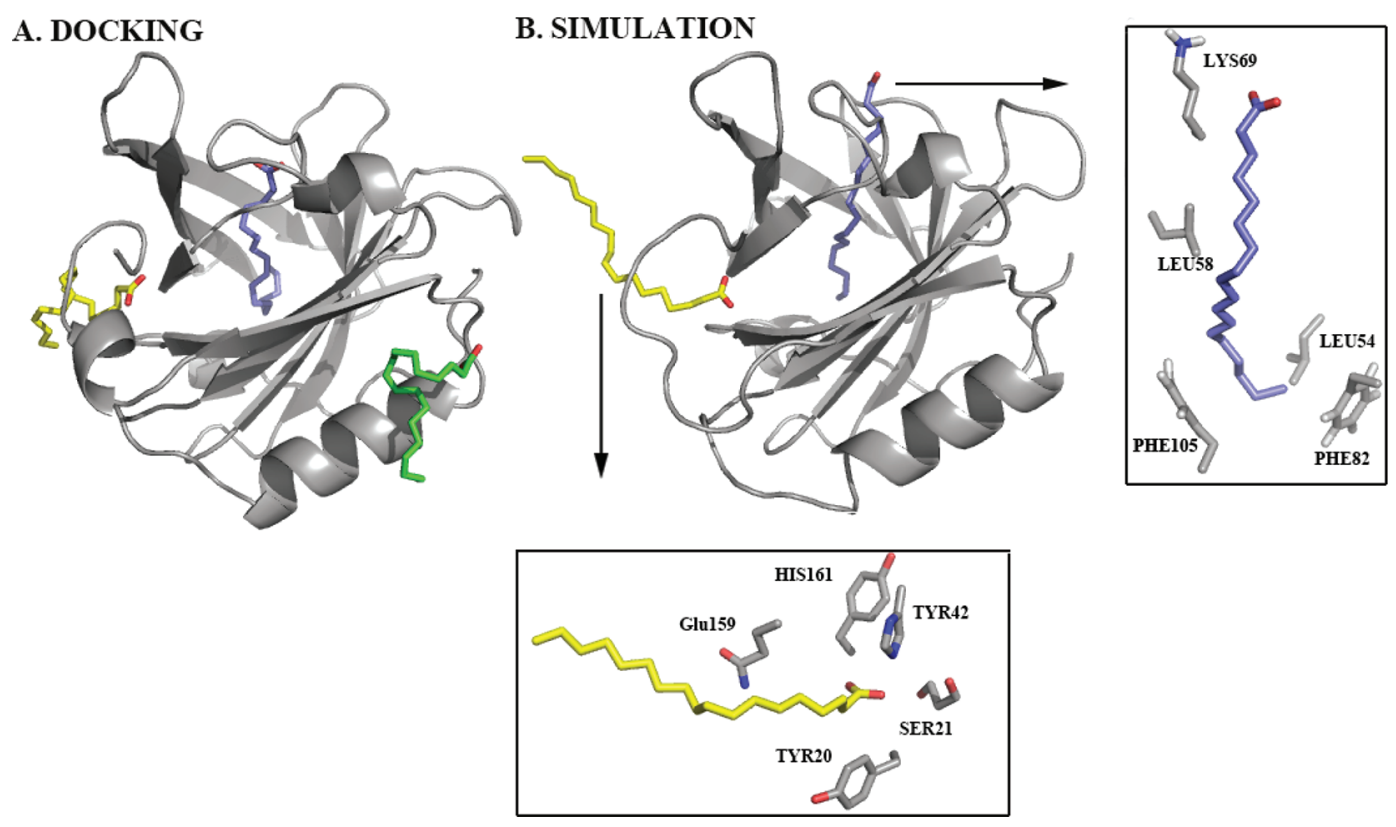

Figure 6. Interaction of palmitic acid with $\beta$-LG: (A) poses obtained by molecular docking with the crystallographic protein structure and (B) external binding sites found in simulation. The ligand in blue corresponds to the fatty acid occupying the protein calyx and is always present together with a second oleic acid (the one in either green or yellow). Residues interacting with the fatty acid in the calyx and external binding site 1 are shown in framed panels.

(149-162), which can be recognized by approximately $90 \%$ of the patients. The second epitopes of $\beta-\mathrm{LG}$ are fragments (1-8) and (25-40), which can be recognized by 58 and $72 \%$ of the patients, respectively. The third epitopes of $\beta$-LG which contain fragments (9-14), (84-91), and (92-100) are still recognized by more than $40 \%$ of patients.

It was shown from the molecule simulation results that OA interacts with residues Lys60, Glu62, Lys69, Tyr20, Tyr42, Ser21, Glu157, and His161 of $\beta$-LG. Remarkably some of these residues are located in the epitopes. Although the conformational changes of $\beta$-LG induced by DHPM may influence the binding process with OA, some epitopes surrounding the binding sites were masked by OA, contributing to the decline of the antigenicity. Furthermore, the conformational changes of $\beta-\mathrm{LG}$, when combined with OA during the DHPM, would also affect its antigenicity. For example, the surface SH contents of $\beta$-LG-OA complexes decreased and the total SH group's contents of $\beta$-LG-OA complexes increased. It is likely that the surrounding ambient of thiol group of Cys121 changed. Therefore, fragments 102-124 may have been destroyed. The changes in synchronous fluorescence spectrum of $\beta$-LG samples for tryptophan (Trp19 and Trp61) and tyrosine residues (Tyr 20, 42, 99, and 102) showed conformational changes around those residues, which indicates that some epitopes, such as f 41-60, f 92-100, and so on, would be modified. In addition, the $\beta$-sheets of $\beta$-LG include some conformational sensitive epitopes. Once the $\beta$-sheets of $\beta$-LG changed after combining with OA during DHPM treatment, those epitopes would also be altered. Consequently, some linear and conformational epitopes of $\beta$-LG, more or less, were destroyed or masked after binding with OA during DHPM treatment, resulting in a gradual reduction of antigenicity of $\beta$-LG-OA complexes.

\section{CONCLUSIONS}

The antigenicity effect and modulation mechanism of OA on $\beta$-LG were investigated by multi-spectroscopic technique and molecule dynamic simulation. Although binding sites of $\beta$-LG combined with OA decreased during the DHPM treatment, $\beta$-LG had a higher binding affinity to OA than that of untreated $\beta-L G$, and the strongest binding affinity was found in $\beta$-LG-OA $(160 \mathrm{MPa})$ samples. In addition, a remarkably steady decline in the antigenicity of $\beta$-LG-OA complex was observed during the DHPM treatment. As per the results obtained in this study, the main reasons for the decline in antigenicity of $\beta$-LG-OA can be due to 2 aspects. On one hand, the conformation of $\beta$-LG changes after binding with OA during the DHPM treatment, reflected by the decrease of fluorescence intensity of tryptophan and tyrosine residues, the increase of surface sulfhydryl group content, the decrease of total sulfhydryl group content, and secondary structure changes of $\beta$-LG. 
These conformational changes may result in the modification of epitopes and the decline of antigenicity. On the other hand, from the molecule simulation results it was observed that some residues of $\beta$-LG that interacted with OA were located in the epitopes. Some epitopes surrounding the binding sites may be masked by $\mathrm{OA}$, resulting in a decline of the antigenicity. In consequence, the conformational changes and the interaction between $\beta$-LG and OA during DHPM treatment simultaneously influenced the antigenicity of $\beta-\mathrm{LG} / \mathrm{OA}$ complex.

\section{ACKNOWLEDGMENTS}

This study was supported financially by the National Natural Science Foundation of China (21366021 and 31560435), the Research Foundation for Young Scientists of State Key Laboratory of Food Science and Technology, Nanchang University, China (no. SKLFQN-201518), and the Natural Science Foundation of Jiangxi Province, China (20161BAB214162).

\section{REFERENCES}

Barbiroli, A., F. Bonomi, P. Ferranti, D. Fessas, A. Nasi, P. Rasmussen, and S. Iametti. 2011. Bound fatty acids modulate the sensitivity of bovine $\beta$-lactoglobulin to chemical and physical denaturation. J. Agric. Food Chem. 59:5729-5737.

Besler, M., H. Steinhart, and A. Paschke. 2001. Stability of food allergens and allergenicity of processed foods. J. Chromatogr. B Biomed. Sci. Appl. 756:207-228.

Bussi, G., D. Donadio, and M. Parrinello. 2007. Canonical sampling through velocity rescaling. J. Chem. Phys. 126:014101.

Chen, W., M. Hwang, C. Liau, J. Ho, K. Hong, and S. Mao. 2005. $\beta$-Lactoglobulin is a thermal marker in processed milk as studied by electrophoresis and circular dichroic spectra. J. Dairy Sci. $88: 1618-1630$.

Croguennec, T., D. Molle, R. Mehra, and S. Bouhallab. 2004. Spectroscopic characterization of heat-induced nonnative beta-lactoglobulin monomers. Protein Sci. 13:1340-1346.

Darden, T., D. York, and L. Pedersen. 1993. Particle mesh Ewald: An $\mathrm{N} \log (\mathrm{N})$ method for Ewald sums in large systems. J. Chem. Phys. 98:10089.

de la Hoz, L., and F. M. Netto. 2008. Structural modifications of $\beta$-lactoglobulin subjected to gamma radiation. Int. Dairy J. 18:1126-1132.

Dufour, E., P. Roger, and T. Haertlé. 1992. Binding of benzo ( $\alpha$ ) pyrene, ellipticine, and cis-parinaric acid to $\beta$-lactoglobulin: Influence of protein modifications. J. Protein Chem. 11:645-652.

Ellman, G. L. 1959. Tissue sulfhydryl groups. Arch. Biochem. Biophys. 82:70-77.

Evoli, S., R. Guzzi, and B. Rizzuti. 2014. Molecular simulations of beta-lactoglobulin complexed with fatty acids reveal the structural basis of ligand affinity to internal and possible external binding sites. Proteins 82:2609-2619.

Fang, B., M. Zhang, M. Tian, and F. Z. Ren. 2015. Self-assembled beta-lactoglobulin-oleic acid and beta-lactoglobulin-linoleic acid complexes with antitumor activities. J. Dairy Sci. 98:2898-2907.

Frapin, D., E. Dufour, and T. Haertle. 1993. Probing the fatty acid binding site of $\beta$-lactoglobulins. J. Protein Chem. 12:443-449.

Funtenberger, S., E. Dumay, and J. C. Cheftel. 1997. High pressure promotes $\beta$-lactoglobulin aggregation through $\mathrm{SH} / \mathrm{S}-\mathrm{S}$ interchange reactions. J. Agric. Food Chem. 45:912-921.
Iametti, S., P. Transidico, F. Bonomi, G. Vecchio, P. Pittia, P. Rovere, and G. Dall'Aglio. 1997. Molecular modifications of $\beta$-lactoglobulin upon exposure to high pressure. J. Agric. Food Chem. 45:23-29.

Jensen, R. G. 2002. The composition of bovine milk lipids: January 1995 to December 2000. J. Dairy Sci. 85:295-350.

Keppler, J. K., F. D. Sonnichsen, P. C. Lorenzen, and K. Schwarz. 2014. Differences in heat stability and ligand binding among betalactoglobulin genetic variants A, B and C using (1)H NMR and fluorescence quenching. Biochim. Biophys. Acta 1844:1083-1093.

Kleber, N., I. Krause, S. Illgner, and J. Hinrichs. 2004. The antigenic response of $\beta$-lactoglobulin is modulated by thermally induced aggregation. Eur. Food Res. Technol. 219:105-110.

Le Maux, S. S. Bouhallab, L. Giblin, A. Brodkorb, and T. Croguennec. 2013. Complexes between linoleate and native or aggregated $\beta$-lactoglobulin: Interaction parameters and in vitro cytotoxic effect. Food Chem. 141:2305-2313.

Liskova, K., M. A. E. Auty, V. Chaurin, S. Min, K. H. Mok, N. O'Brien, A. L. Kelly, and A. Brodkorb. 2011. Cytotoxic complexes of sodium oleate with beta-lactoglobulin. Eur. J. Lipid Sci. Technol. 113:1207-1218.

Loch, J., A. Polit, A. Gorecki, P. Bonarek, K. Kurpiewska, M. Dziedzicka-Wasylewska, and K. Lewinski. 2011. Two modes of fatty acid binding to bovine beta-lactoglobulin-crystallographic and spectroscopic studies. J. Mol. Recognit. 24:341-349.

Loch, J. I., P. Bonarek, A. Polit, D. Ries, M. Dziedzicka-Wasylewska, and K. Lewinski. 2013. Binding of 18-carbon unsaturated fatty acids to bovine beta-lactoglobulin-structural and thermodynamic studies. Int. J. Biol. Macromol. 57:226-231.

Martoňák, R., A. Laio, and M. Parrinello. 2003. Predicting crystal structures: The Parrinello-Rahman method revisited. Phys. Rev. Lett. 90:075503.

Meng, X., Y. Bai, J. Gao, X. Li, and H. Chen. 2017. Effects of high hydrostatic pressure on the structure and potential allergenicity of the major allergen bovine $\beta$-lactoglobulin. Food Chem. 219:290296.

O'Neill, T., and J. Kinsella. 1988. Effect of heat treatment and modification on conformation and flavor binding by $\beta$-lactoglobulin. J. Food Sci. 53:906-909.

Oostenbrink, C., A. Villa, A. E. Mark, and W. F. van Gunsteren. 2004. A biomolecular force field based on the free enthalpy of hydration and solvation: The GROMOS force-field parameter sets 53A5 and 53A6. J. Comput. Chem. 25:1656-1676.

Pérez, M. D., and M. Calvo. 1995. Interaction of $\beta$-lactoglobulin with retinol and fatty acids and its role as a possible biological function for this protein: A review. J. Dairy Sci. 78:978-988.

Pettersen, E. F., T. D. Goddard, C. C. Huang, G. S. Couch, D. M. Greenblatt, E. C. Meng, and T. E. Ferrin. 2004. UCSF ChimeraA visualization system for exploratory research and analysis. J. Comput. Chem. 25:1605-1612.

Pronk, S., S. Pall, R. Schulz, P. Larsson, P. Bjelkmar, R. Apostolov, M. R. Shirts, J. C. Smith, P. M. Kasson, D. van der Spoel, B. Hess, and E. Lindahl. 2013. GROMACS 4.5: A high-throughput and highly parallel open source molecular simulation toolkit. Bioinformatics 29:845-854.

Qi, X. L., C. Holt, D. McNulty, D. T. Clarke, S. Brownlow, and G. R. Jones. 1997. Effect of temperature on the secondary structure of beta-lactoglobulin at $\mathrm{pH}$ 6.7, as determined by $\mathrm{CD}$ and IR spectroscopy: A test of the molten globule hypothesis. Biochem. J. 324:341-346

Rizzuti, B., M. Pantusa, and R. Guzzi. 2010. The role of Lys525 on the head-group anchoring of fatty acids in the highest affinity binding site of albumin. Spectr. Int. J. 24:159-163.

Ron, N., P. Zimet, J. Bargarum, and Y. D. Livney. 2010. Beta-lactoglobulin-polysaccharide complexes as nanovehicles for hydrophobic nutraceuticals in non-fat foods and clear beverages. Int. Dairy J. 20:686-693.

Sava, N., I. Van der Plancken, W. Claeys, and M. Hendrickx. 2005. The kinetics of heat-induced structural changes of $\beta$-lactoglobulin. J. Dairy Sci. 88:1646-1653.

Selo, I., G. Clement, H. Bernard, J. M. Chatel, C. Creminon, G. Peltre, and J. M. Wal. 1999. Allergy to bovine $\beta$-lactoglobulin: 
Specificity of human IgE to tryptic peptides. Clin. Exp. Allergy 29:1055-1063.

Shibayama, N. 2008. Circular dichroism study on the early folding events of beta-lactoglobulin entrapped in wet silica gels. FEBS Lett. 582:2668-2672.

Shimada, K., and J. C. Cheftel. 1988. Determination of sulfhydryl groups and disulfide bonds in heat-induced gels of soy protein isolate. J. Agric. Food Chem. 36:147-153.

Shpigelman, A., G. Israeli, and Y. D. Livney. 2010. Thermally-induced protein-polyphenol co-assemblies: Beta lactoglobulin-based nanocomplexes as protective nanovehicles for EGCG. Food Hydrocoll. 24:735-743.

Simion, A. M., I. Aprodu, P. Alexe, and N. Stanciuc. 2015b. Influence of $\mathrm{pH}$ and heat treatment on beta-lactoglobulin-oleic acid complex. An. Univ. Dunarea de Jos Galati Fasc. VI Food Technol. 39:64-76.

Simion, A.-M., I. Aprodu, L. Dumitrașcu, G. E. Bahrim, P. Alexe, and N. Stănciuc. 2015a. Probing thermal stability of the $\beta$-lactoglobulin-oleic acid complex by fluorescence spectroscopy and molecular modeling. J. Mol. Struct. 1095:26-33.

Trott, O., and A. J. Olson. 2010. AutoDock Vina: Improving the speed and accuracy of docking with a new scoring function, efficient optimization, and multithreading. J. Comput. Chem. 31:455-461.

Varlan, A., and M. Hillebrand. 2010. Bovine and human serum albumin interactions with 3-carboxyphenoxathiin studied by fluorescence and circular dichroism spectroscopy. Molecules 15:3905-3919.

Wu, X., H. Wu, M. Liu, Z. Liu, H. Xu, and F. Lai. 2011. Analysis of binding interaction between (-)-epigallocatechin (EGC) and betalactoglobulin by multi-spectroscopic method. Spectrochim. Acta A Mol. Biomol. Spectrosc. 82:164-168.

Wu, X., X. Zhong, M. Liu, L. Xia, K. Feng, H. Wu, and Z. Liu. 2013. Reduced allergenicity of $\beta$-lactoglobulin in vitro by tea catechins binding. Food Agric. Immunol. 24:305-313.
Yang, M. C., H. H. Guan, M. Y. Liu, Y. H. Lin, J. M. Yang, W. L. Chen, C. J. Chen, and S. J. Mao. 2008. Crystal structure of a secondary vitamin $\mathrm{D}_{3}$ binding site of milk $\beta$-lactoglobulin. Proteins 71:1197-1210.

Zhang, J., X. Liu, M. Subirade, P. Zhou, and L. Liang. 2014. A study of multi-ligand beta-lactoglobulin complex formation. Food Chem. 165:256-261.

Zhong, J., X. Cai, C. Liu, W. Liu, Y. Xu, and S. Luo. 2016. Purification and conformational changes of bovine PEGylated beta-lactoglobulin related to antigenicity. Food Chem. 199:387-392.

Zhong, J., C. Liu, W. Liu, X. Cai, Z. Tu, and J. Wan. 2011. Effect of dynamic high-pressure microfluidization at different temperatures on the antigenic response of bovine $\beta$-lactoglobulin. Eur. Food Res. Technol. 233:95-102.

Zhong, J., S. Luo, C. Liu, and W. Liu. 2014. Steady-state kinetics of tryptic hydrolysis of $\beta$-lactoglobulin after dynamic high-pressure microfluidization treatment in relation to antigenicity. Eur. Food Res. Technol. 239:525-531.

Zhong, J., Y. Tu, W. Liu, S. Luo, and C. Liu. 2015. Comparative study on the effects of nystose and fructofuranosyl nystose in the glycation reaction on the antigenicity and conformation of betalactoglobulin. Food Chem. 188:658-663.

Zhong, J. Z., W. Liu, C. M. Liu, Q. H. Wang, T. Li, Z. C. Tu, S J. Luo, X. F. Cai, and Y. J. Xu. 2012. Aggregation and conformational changes of bovine $\beta$-lactoglobulin subjected to dynamic high-pressure microfluidization in relation to antigenicity. J. Dairy Sci. 95:4237-4245.

Zimet, P., and Y. D. Livney. 2009. Beta-lactoglobulin and its nanocomplexes with pectin as vehicles for $\omega-3$ polyunsaturated fatty acids. Food Hydrocoll. 23:1120-1126. 